\title{
Influence of Age and Experience on Leadership Styles
}

\author{
Asima Mushtaq ${ }^{1}$ and Ishtiaq Hussain Qureshi ${ }^{2}$ and Aakifa Javaid ${ }^{3}$ \\ ${ }^{1 \& 3}$ Researcher, ${ }^{2}$ Assistant Professor (Senior) \\ ${ }^{1,2 \& 3}$ Department of Management Studies, University of Kashmir, Jammu \& Kashmir, India \\ E-Mail: asimamushtaqbhat@gmail.com
}

\begin{abstract}
The aim of this study is to investigate the influence of age and experience on the leadership styles of the managers, in the three selected banks of Kashmir division viz J\&K Bank, SBI and HDFC. The study focuses on two leadership styles, namely transformational and transactional leadership styles. The study reveals that the transformational leadership style is the dominant leadership style among managers of all age and experience groups. Furthermore, the study reveals that the age and experience have no significant influence on leadership styles, although with the increase in age and experience transformational leadership style is exhibited more by the managers.

Keywords: Leadership Styles, Age, Experience, Transformational Leadership Style, Transactional Leadership Style
\end{abstract}

\section{INTRODUCTION}

Leadership is an influence process that enables managers to get their people to do willingly what must be done, do well what ought to be done (Cribbin, 1981). A review of the leadership literature reveals an evolving series of theories from "Great Man" and "Trait" theories to "Transformational" leadership. While earlier theories focused upon the characteristics and behaviours of leaders, later theories began to consider the role of followers and the situational nature of leadership. In the early years leadership was associated with individual skills, characteristics and personal qualities of the leader (Nivala and Hujala, 2002). However, the modern view of leadership proclaims that leadership is not an isolated activity endowed in a single person, but rather a variety of factors contribute to effective leadership. Researchers over time have made attempts to determine the relationship between leadership and various demographic factors as age, gender, experience, educational background etc. Even though most of the researches find significant correlations between leadership and the aforementioned demographic factors, yet others contradict this view.

The studies of Kanter (1977), Herbert and Yost (1979), Eagly (1987), Thompson (2000) and many more have investigated the influence of the leader's gender on the leadership behavior. But, since very limited researches could be found that study the influence of age and experience on leadership style, the current study has thus chosen these demographic factors in order to investigate their influence on the leadership styles.
It is generally perceived that the old people are not able to do certain tasks at the efficiency of the younger people because of their physical weaknesses. But at certain tasks the older people can do better than youngsters (Belal et al., 2010). This is because of the experience they possess which they acquire during the course of their working career. Consequently, they are perceived to give better advices and take better decisions. Many studies on the influence of age and experience on the leadership style of the individuals claim that the differences in age and experience affect the leadership behavior as well. Since, leadership is about understanding the followers better in order to achieve the desired task, so the elder people are supposed to be better leaders than the younger ones. This is because of the reason that with the growing age and experience, people are able to understand their followers better and thus can deal with them in a more positive way (Mirani et al., 2003). Since, no study could be found that focuses on the influence of age and experience on leadership in the organizations of Kashmir division, the current study thus aims to investigate the influence of the two factors on the leadership styles of managers in the three major banks of Kashmir division.

\section{SCOPE OF THE STUDY}

The current study examines the influence of age and experience on leadership styles in the three select banks of Kashmir. The leadership styles chosen for the study include transformational leadership style and transactional leadership style. The study attempts to compare the leadership styles across the age and experience of the managers in order to inspect whether the difference in age and experience causes the difference in leadership styles as well. The study thus makes an attempt to comprehend and examine the importance of age and experience vis-à-vis leadership styles in the select banks.

\section{REVIEW OF LITERATURE}

Leadership is a process whereby an individual influences a group of individuals to achieve a common goal (Northouse, 2010) and the individual who leads a group of people towards a common goal is known as the leader (Andrew, 2009). A leader influences his followers to achieve the specified objectives (Sheikh, 2001). Literature review of leadership reveals an evolving series of theories from "Great Man" and "Trait" theories to "Transformational" leadership. Different theories of leadership classify 
leadership in different ways. While earlier theories tend to focus upon the characteristics and behaviours of successful leaders, later theories began to consider the role of followers and the situational nature of leadership. A recent view of leadership says that leadership is not an isolated activity endowed in a single person, but rather that a variety of people contribute to effective leadership. Each leadership style has its own merits and demerits. None can be applied universally in all circumstances. Bass (1990) asserts that the leader has to choose his/her leadership style depending on the situation and the followers in order to be effective.

Leadership styles may vary vis-à-vis the various demographic factors of the leader and the followers as well. Various studies have investigated the influence of various demographics like age, gender, culture, educational background, and experience on leadership. The current study has chosen two demographic factors viz age and experience in order to study their influence on leadership styles of managers in the select organizations of Kashmir division. It is a common perception that the age and experience play important roles in leadership behaviors. However from the literature, it was found that some researches find a significant correlation between age and leadership, whereas others find a zero correlation. Similarly some studies find strong relationship between experience and leadership styles whileas others find a little or no relationship. However, very few researches could be found that negate these relationships.

Cagle (1988) regards age as one of the main factors that determines the leadership style. Mirani et al., (2003) argue that age significantly influences leadership. Furthermore, the studies of (Rasor, 1995; Payden, 1997; Belal et al., 2010) show prominent differences in leadership style due to age. Titus Oshagbemi (2004) claims that the younger and older managers adopt different leadership styles; older managers favor more participation in comparison with younger managers.

Kearney (2008) states that when the leaders and followers are of similar age, the feeling of distrust can arise as to why one has been chosen as a leader and not the other. Older leaders give the impression that they have more experience and thus their followers accept them as leaders more easily (Kearney 2008). The researcher further suggests that transactional styles of leadership style is more appropriate for young leaders whileas transformational leadership is more suited for older and experienced leaders. This is because with an older leader, the team may be more open to a leader's transformational behaviors as the team members may be more accepting of the leader's special status. Furthermore, the researchers believe that experience might play an important role in leadership behaviors.

Trompenaars (1993) states that leadership styles differ from culture to culture and country to country depending upon life patterns, beliefs and value system and experience of the people.
Ahiazu (1989) asserts that in many cultures it is believed that people get wiser due to more exposure and experience. For example in African culture, experience is considered as a priority for leadership positions in different organizations. The studies of Cagle (1988) Katozai, (2005) and Van Vugt (2006) also believe that experience has a significant influence on leadership. Contrary to the above studies, few researches cancel out the influence of age and experience on leadership. Gronn (1986) argues that leadership style is rooted in the condition of workplace and less dependent upon personality attributes like age and experience. The studies of Gilbert et al., (1990), Vecchio, 1993, Zacher et al., 2011) also endorse the fact that age does not significantly influence the leadership styles of managers.

\section{HYPOTHESES}

Following hypotheses are proposed for the study:

$H_{l}$ : There is no significant difference in leadership styles vis-à-vis the age of managers.

$\mathrm{H}_{2}$ : There is no significant difference in leadership styles vis-à-vis the experience of managers.

\section{RESEARCH METHODOLOGY AND DATA COLLECTION}

Explanatory research design was followed for the present study. The target population for the study constituted the managerial personnel of the three major banks of Kashmir division: JK Bank, SBI, and HDFC. The total population for the study constituted 905 managers out of which a representative random sample of 100 managers was selected for the purpose of primary data collection. The sample size of 100 was calculated with the help of online sample calculator with confidence level $95 \%$ and confidence interval (margin of error) of 5.

The primary data was collected from the respondents from the selected organizations with the help of a structured questionnaire. Leadership styles were measured using Multifactor Leadership Questionnaire (MLQ) (Form 5xshort) developed by Bass and Avolio (1995). The secondary data was collected from various books, journals, and other print and electronic publications.

\section{RESULTS AND DISCUSSION}

The difference in leadership styles vis-à-vis the age and experience of managers banks was analyzed to see whether the leadership styles adopted by the managers varied significantly with respect to their ages and experiences. First the descriptive were calculated for all the five age groups regarding their leadership styles. It was found that the age group "35-40" scored highest on transformational leadership style and the age group "Below 35" scored lowest on transformational leadership. Contrarily, the age group "Below 35" scored highest on transactional leadership style while as the age group 46-50 scored lowest on transactional leadership style. Table I gives the details: 
TABLe I Age Wise Descriptive StATISTICs Of MANAGers' LEADERSHIP STYLES

\begin{tabular}{|c|l|c|c|}
\hline \multicolumn{2}{|c|}{ Age } & TRF & TRNS \\
\hline \multirow{4}{*}{$\begin{array}{c}\text { Below } \\
35\end{array}$} & Mean & 3.9170 & 3.8765 \\
\cline { 2 - 4 } & $\mathrm{N}$ & 17 & 17 \\
\cline { 2 - 4 } & Std. Deviation & .41441 & .36662 \\
\hline \multirow{4}{*}{$35-40$} & Mean & 4.2353 & 3.6214 \\
\cline { 2 - 4 } & $\mathrm{N}$ & 14 & 14 \\
\cline { 2 - 4 } & Std. Deviation & .48944 & .83590 \\
\hline \multirow{4}{*}{$41-45$} & Mean & 4.1218 & 3.5286 \\
\cline { 2 - 4 } & N & 14 & 14 \\
\cline { 2 - 4 } & Std. Deviation & .28207 & .33381 \\
\hline \multirow{4}{*}{$46-50$} & Mean & 3.8569 & 3.4733 \\
\cline { 2 - 4 } & N & 30 & 30 \\
\cline { 2 - 4 } & Std. Deviation & .54390 & .50714 \\
\hline \multirow{3}{*}{$\begin{array}{c}\text { Above } \\
50\end{array}$} & Mean & 4.1035 & 3.6600 \\
\cline { 2 - 4 } & N & 25 & 25 \\
\cline { 2 - 4 } & Std. Deviation & .46264 & .68496 \\
\hline
\end{tabular}

Source: Data compilation by the scholar for the present study. Note: TRF= Transformational leadership Style, TRNS= Transactional Leadership Style
Next, in order to check whether the difference in mean scores was significant or not, one way ANOVA was applied, which gave the following results.

It was found that the leadership styles did not vary significantly with respect to the age of managers with $p$ value of .070 and .472 in transformational and transactional leadership styles respectively. Hence, enough evidence could not be found to reject the hypothesis H1 which says "There is no significant difference in leadership styles vis-àvis the age of managers. Next, the Descriptive were calculated for all the five experience groups regarding their leadership styles. It was found that the managers having 510 years of experience scored highest on transformational leadership style while as managers having less than 5 years of experience scored lowest on transformational leadership style.

On the other hand, managers having less than 5 years scored highest on transactional leadership style and while as managers having 11-15 years of experience scored lowest on transactional leadership style. Table III gives the details:

TABLE II Age Wise COMPARISON OF LEADERShIP STYLES OF MANAGERS

\begin{tabular}{|c|l|c|c|c|c|c|}
\hline \multicolumn{2}{|c|}{ Leadership Styles } & Sum of Squares & df & Mean Square & F & Sig \\
\hline \multirow{4}{*}{ TRF } & Between Groups & 1.947 & 4 & .487 & 2.244 & .070 \\
\cline { 2 - 7 } & Within Groups & 20.612 & 95 & .217 & & \\
\cline { 2 - 7 } & Total & 22.560 & 99 & & & \\
\hline \multirow{4}{*}{ TRNS } & Between Groups & 1.179 & 4 & .295 & .891 & .472 \\
\cline { 2 - 7 } & Within Groups & 31.401 & 95 & .331 & & \\
\cline { 2 - 7 } & Total & 32.580 & 99 & & & \\
\hline
\end{tabular}

Source: Data compilation by the scholar for the present study

Note: $\mathrm{TRF}=$ Transformational leadership Style, TRNS $=$ Transactional Leadership Style

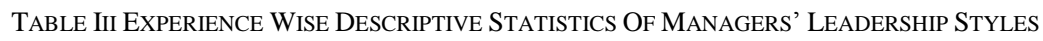

\begin{tabular}{|c|c|c|c|}
\hline \multicolumn{2}{|c|}{ Experience } & TRF & TRNS \\
\hline \multirow{3}{*}{ Less than 5 years } & Mean & 3.8147 & 3.8125 \\
\hline & $\mathrm{N}$ & 9 & 9 \\
\hline & Std. Deviation & .40497 & .37572 \\
\hline \multirow{3}{*}{$5-10$ years } & Mean & 4.1838 & 3.8000 \\
\hline & $\mathrm{N}$ & 16 & 16 \\
\hline & Std. Deviation & .41532 & .33166 \\
\hline \multirow{3}{*}{$11-15$ years } & Mean & 4.0924 & 3.3929 \\
\hline & $\mathrm{N}$ & 14 & 14 \\
\hline & Std. Deviation & .44663 & .81568 \\
\hline \multirow{3}{*}{$16-20$ years } & Mean & 3.8824 & 3.4000 \\
\hline & $\mathrm{N}$ & 20 & 20 \\
\hline & Std. Deviation & .45183 & .42797 \\
\hline \multirow{3}{*}{ More than 20 years } & Mean & 4.0588 & 3.6415 \\
\hline & $\mathrm{N}$ & 41 & 41 \\
\hline & Std. Deviation & .52564 & 61032 \\
\hline
\end{tabular}

Source: Data compilation by the scholar for the present study Note: $\mathrm{TRF}=$ Transformational leadership Style, TRNS= Transactional Leadership Style 
Next, one way ANOVA was applied so as to verify whether the difference in mean scores was significant or not, which

gave the following results.

TABLE IV EXPERIENCE WISE COMPARISON OF LEADERSHIP STYLES OF MANAGERS

\begin{tabular}{|c|l|c|c|c|c|c|}
\hline \multicolumn{2}{|c|}{ Leadership Styles } & Sum of Squares & df & Mean Square & F & Sig. \\
\hline \multirow{3}{*}{ TRF } & Between Groups & 1.578 & 4 & .394 & 1.786 & .138 \\
\cline { 2 - 7 } & Within Groups & 20.982 & 95 & .221 & & \\
\cline { 2 - 7 } & Total & 22.560 & 99 & & & \\
\hline \multirow{3}{*}{ TRNS } & Between Groups & 2.554 & 4 & .638 & 2.020 & .098 \\
\cline { 2 - 8 } & Within Groups & 30.026 & 95 & .316 & & \\
\cline { 2 - 7 } & Total & 32.580 & 99 & & & \\
\hline
\end{tabular}

Note: TRF $=$ Transformational leadership Style, TRNS= Transactional Leadership Style

The difference was found to be insignificant with $\mathrm{p}$ value of 138 and .098 in transformational and transactional leadership styles respectively. It specifies that the leadership styles did not vary significantly with respect to the experience of managers. So enough evidence could not be found to reject the hypothesis H2, "There is no significant difference in leadership styles vis-à-vis the experience of managers.

\section{FINDINGS OF THE STUDY}

Based upon the above analysis and interpretation of data, the study comes out with following findings

1. Transformational leadership style was found to be the dominant leadership style of managers irrespective of their ages and experiences.

2. The young managers were found to score lower on transformational leadership style compared to the elder managers. Among all the age groups, managers falling in the age group of 35-40 years were found to score highest on transformational leadership style and the managers having below 30 years of age were found to score lowest on transformational leadership style.

3. As far as transactional leadership style is concerned, young mangers were found to score more than the elder ones. Managers having below 30 years of age were found to score highest on transactional leadership style and the managers in the age group of 46-50 were found to score lowest on transactional leadership style.

4. Likewise the managers with more experience were found to be more transformational than the managers with less experience. Managers having 5-10 years of experience were found to be most transformational whereas the managers having below five years of experience were found to be least transformational.

5. Just as the young managers were found to score higher on transactional leadership style, similarly, the managers with less experience were found to score more on transactional leadership style than the managers with more experience. The managers having less than 5 years of experience were found to score highest on transactional leadership styles and the managers having 11-15 years of experience were found to score lowest on transactional leadership styles.

6. Although the mean scores varied among the managers of all age and experience groups, however, with further examination, the differences in the leadership styles across all age and experience groups were found to differ insignificantly. It implies that age and experience do not considerably influence the leadership styles.

\section{CONCLUSION}

The study attempted to examine the influence of age and experience on leadership styles. The study comes up with the conception that the age and experience have no considerable influence on the leadership styles of managers. The mean scores imply that the managers start with adopting almost equivalent amount of transactional and transformational leadership styles but in their middle ages move mostly towards transformational leadership style. Similarly, the managers with less experience start off with adopting equivalent amount of transactional and transformational leadership styles but with time move mostly towards transformational leadership style. Furthermore, the study found out that transformational leadership style was most preferred leadership style among all age and experience groups. In the contemporary business setup transformational leadership styles is gaining more importance and acceptance. Managers of all ages and experiences are seen interested in adopting more of transformational leadership style as this style is believed to be positively influencing organisational performance (Obiwuru et al., 2011; Islam et al., 2012; Ravazadeh and Ravazadeh 2013; Skarholt et al., 2015).

\section{REFERENCES}

[1] Ahiazu, A. I. (1989). The Theory A system of work organization for the modern African workplace. International Studies of Management and Organization, 19(1), 6-27.

[2] Andrew J. DuBrin. (2009). Leadership: New York, USA: Houghton Mifflin Company.

[3] Bass, B. M., \& Avolio, B. J. (1995). MLQ: Multifactor Leadership Questionnaire for Research: Permission Set. Redwood City, CA: Mind Garden. 
[4] Bass, B. M. (1990). Handbook of leadership: Theory, research, \& managerial applications, Third edition. New York: Free Press.

[5] Belal A. Kaifi, Bahaudin G. Mujtaba (2010), Transformational Leadership of Afghans and Americans: A Study of Culture, Age and Gender, Journal of Service Science \& Management, DOAJ.

[6] Cagle, S. G. (1988). Fiedler's Contingency Theory of Leadership Effectiveness and Appointment of a Committee Chairperson. Dissertation Abstracts International, 50(07), 2842.

[7] Cribbin, J. J. (1981). Leadership: strategies for organizational effectiveness. New York: AMACOM

[8] Eagly, A.H. (1987). Sex differences in social behavior: A social-role interpretation. Hillsdale, NJ: Erlbaum.

[9] Gilbert, G. R., Collins, R. W., \& Brenner, R. (1990). Age and leadership effectiveness: From the perceptions of the follower. Human Resource Management, 29, 187-196.

[10] Gronn, P. (1986). The psycho-social dynamics of leading and following. Victoria: Deakin University Press

[11] Herbert S. G. and Yost E. B. (1979). Women as Effective Managers: A Strategic Model for Overcoming the Barriers. Human Resource Management 7, 18-25.

[12] Islam, T., Aamir, M., Ahmed, I., \& Muhammad, S. K. (2012). The impact of transformational and transactional leadership styles on the motivation and academic performance of students at university level. Journal of Educational and Social Research, 2(2), 237-244.

[13] Kanter, R. M. (1977). Men and Women of the Corporation. New York: Basic, 166

[14] Katozai, M. A. (2005). A Comprehensive Study of Education for Prospective Headmasters and Headmistresses, University publisher, Doger unique book Peshawar.

[15] Kearney, E. (2008), Age differences between leader and followers as a moderator of the relationship between transformational leadership and team performance, Journal of Occupational \& Organizational Psychology, 81(4), 803-811.

[16] Mirani, Z. D., Narejo, M. A., \& Kumbhar, M. I. (2003). Essential leadership competencies needed in agricultural occupations as identified by agricultural leaders in district Hyderabad, Sindh. Pakistan Journal of Applied Sciences, 3(1), 30-35.

[17] Nivala, V. \& Hujala, E. (eds) (2002), Leadership in early childhood education, Cross-cultural perspectives, Oulu, Finland: Department of Educational Sciences and Teacher Education, Early Childhood Education, University of Oulu, Retrieved from: http://herkules. oulu.fi/isbn9514268539/isbn9514268539.pdf

[18] Northouse, P. G. (2010). Leadership: Theory and practice (5th Ed.). Thousand Oaks, CA: Sage Publications.
[19] Obiwuru, T. C., Okwu, A. T., Akpa, V.O., \& Nwankwere, I. A (2011). Effects of leadership style on organizational performance: A survey of selected small scale enterprises in Ikosi-Ketu council development area of Lagos State, Nigeria. Australian Journal of Business and Management Research, 1(7), 100.

[20] Payden, B. L. (1997). The relationship between perceived leadership behaviors and job satisfaction based on age, gender, and education level variables. Dissertation Abstracts International: Section A Humanities \& Social Sciences, 57(7-A), 3127.

[21] Rasor, C. E. (1995). An analysis of the relationship between personality preference traits of executive level and mid-level law enforcement/corrections leaders and exemplary leadership practices. Dissertation Abstracts International: Section A: Humanities \& Social Sciences, 56(4-A), 1436.

[22] Ravazadeh, N., \& Ravazadeh, A. (2013). The effect of transformational leadership on staff empowerment. International Journal of Business and Social Science, 4(10).

[23] Sheikh, A. G. (2001). Leadership Styles as Viewed by Secondary School Head Teachers of Lahore City, Institute of Leadership and Management, Lahore, Affiliated with Hamdard University, Karachi Pakistan. Master thesis in education Studies of Management and Organization, 19(1), 6-27.

[24] Skarholt, K., Blix, E. H., Sandsund, M., \& Andersen, T. K. (2015) Health promoting leadership practices in four Norwegian industries. Health Promotion International, 1(10).

[25] Thompson, M.D. (2000). Gender, leadership orientation, and effectiveness: Testing the theoretical models of Bolman, Deal, and Quinn. Sex Roles, 42, 969-993.

[26] Titus Oshagbemi, (2004) Age influences on the leadership styles and behavior of managers, Employee Relations, 26(1),14 - 29

[27] Trompenaars, F. (1993). Riding the waves of culture: Understanding diversity in global business. Chicago, IL: Irwin.

[28] Van Vugt. M (2006), Evolutionary origins of leadership and followership, Personality \& Social Psychology Review, 10(4), 354371.

[29] Vecchio, R. P. (1993). The impact of differences in subordinate and supervisor age on attitudes and performance. Psychology and Aging, 8, 112-119

[30] Zacher, H., Rosing, K. \& Frese, M. (2011a) Age and leadership: The moderating role of legacy beliefs. The Leadership Quarterly, 22, 4350 . 